Research Paper

\title{
Learning Mathematics: One Minute
}

\section{Amir Zuhairi Zakaria ${ }^{1}$, Haslina Hassan ${ }^{1}$, Hanasrullah Halim ${ }^{1}$, Wan Amirah Najwa Wan Idris $^{1}$, Muhammad Asyraf Abdullah Zawawi², Nur Fathihah Mansor ${ }^{3}$}

${ }^{1}$ Program of Game Development, Department of Computing, Faculty of Arts, Computing, and Industry Creative. Universiti Pendidikan Sultan Idris, Malaysia.

${ }^{2}$ Program of Information Technology (Education), Department of Computing, Faculty of Arts, Computing, and Industry Creative. Universiti Pendidikan Sultan Idris, Malaysia.

${ }^{3}$ Convep Mobilogy Sdn. Bhd. Oasis Damansara, 47301 Petaling Jaya, Selangor Darul Ehsan, Malaysia.

\section{Article History \\ Received:}

04.08.2020

Revised:

15.09.2020

Accepted:

25.09.2020

*Corresponding Author:

Haslina Hassan

Email:

haslina@fskik.upsi.edu.my

This is an open access article, licensed under: $\mathrm{CC}-\mathrm{BY}-\mathrm{SA}$
Abstract: This game is made with purpose to educate student in terms of mathematical skill combined with fun adventure game. The target audience is the students should be primary-school (10-13 years old). This is an educational game and made on purpose to create a difference method to present solving a mathematical problem to the audience. The user will play a game where the character is chased by a dog and must avoid obstacles such as river. In each level of the game, the user must find a door in which they must solve the mathematical question as pass code. Successful in solving the mathematical question will bring user to another level. This game is made with 3 level and must be completed within 1 minute. This game can be used as a tool for learning. The level of mathematical questions is simple mathematical quiz, designed with objective to teach early age students.

Keywords: Educational Game, Fun Adventure, Learning Mathematics. 


\section{Introduction}

Advanced development in industry 4.0 during recent years have made many researchers tried to blend game design with educational purposes. The traditional classroom educational method heavily relies on the students ability to active listening during certain period of times, thus this method is less engaging because students can easily prone to boredom. The development of educational game was tried to bridge this gap. By designing an engaging game adventure with educational value, will help students become more active and thus can learn more.

Several educational games has been developed during recent years in Malaysia, such as Genius Kids [1] which help to educate children learn to count, 7-Gates [2] which help secondary students to learn about logic gates by solving puzzle game, and AR-LoGates [3] which help students learn about logic gates through Augmented Reality.

This project specifies a concept design for the gameplay of a game with provisional name "One Minute". This game is based on Vector that invented by Cyprian Studio Nekki in 2010. The game has an appropriate method of action and solving the problem for student to learn, a blended between action and educational games. Making this game absolutely has the aim for the future especially in education. In fact, nowadays we have been involved to further high technologies to all teen generation who struggle in learning about the system in industry 4.0. All teen generation must have a skill on mathematical formulas to learning more about the system in industry 4.0. So, as a game designer and developer game are looking forward to the teenager and country. The teenagers also must expert in mathematical formulas because Malaysia nowadays using purchase system to buy or sell something.

The One Minute action and educational game intended to create a new opportunity to the one who are not a bookworm also the person who love in gaming but want to do gaming in benefits sight. Striking the difference in this game, the developer uses a simple platform with different weather on the different level of the game. One Minute title presented where the user can explore the world with difference weather.

This game will present an introduction level on starting the game before going to the platform game which is the user needs run from the dog while overcoming obstacle then find a door before time ended on every level and how to control the player and using the button. The introduction level can be used for teaching and learning especially for a briefing session on how is the One Minute game to be played. After that, the user can know and proceed what to do while playing the game and know how to control the player.

Despite, the user must run from the dog to avoid being caught and the user must find a door then player must answer the question before time ended to complete the level and go to the next level. The user needs to be fast to finish every level. There's no map to guide the user when searching the door. Also, every level has a river, whenever player falls into the river causes player died and the lose screen will be displayed, user can play again the level if click the restart button. Every level the game developer creates a button after complete the question to the next level. The game developer only made 3 levels if there's no objection or an opportunity to the game developer and the supervisor to innovate One Minute to be more advanced, the game developer will make it more live for the future.

\section{Synopsis}

Jack was a normal student. Jack was not good at studying and had a lot of imagination. One day, Jack took the math exam. Jack couldn't answer the math test. As a result, Jack begins to imagine being trapped somewhere and being chased by a dog. Jack must escape from being caught by the dog by running and finding the door to save himself. In that place Jack will face many challenges and obstacles. Upon arriving at the door, he had to solve a mathematical question to open the door.

The objective to One Minute is to make the user think really fast while playing the game and to complete the game, also to make the user learning about mathematical formulas. Although, Games for learning often aim to change user identities (e.g., helping student to be more alert and helping the user to solve the problem in a short time). An alternative approach to changing player identity is to design game the better account for the nested identities of students as players [4].

\section{Methodology}

One Minute as a game title, to show or give symbols meaning to target audience that the user must complete the game in one minute. This gives a sense of thriller and fun for the user. Moreover, the game developer to this game think by making an adorable character, especially with the story-telling 
Amir Zuhairi Zakaria, Haslina Hassan, Hanasrullah Halim, Wan Amirah Najwa Wan Idris, Muhammad Asyraf Abdullah Zawawi, Nur Fathihah Mansor.

animation would bring the most enjoyable and entertaining experience, so it would be more welcomed by the audience.

\subsection{Genre}

The genre of the game is action and educational game and sub-genre is platform game. The action genre in this game about the player must run from the dog and avoid from being caught. Educational genre in this game giving the player must solve the mathematical problem to complete the level and go to the next level. Also, the game is the platform game type.

\subsection{Target Demographic}

The target audience is the students should be primary-school. This game is a serious game/an educational game and made on purpose to create a difference method to present solving a mathematical problem to the audience. The game can be used as a learning tools for students (10-13 years old).

\subsection{High Concept}

High concept for this game is made with content to tell the audience that the game developer focused on the action skill, to be fast and solving the mathematical problem. Description: the only way for the player to pass the level in this game, with speed skills and the mathematical formulas the player can complete the level and go to the next level. Without speed skills and mathematical knowledge, the player will lose the game and being caught by the dog.

\subsection{Unique Selling Point}

The game has a complex combination platform an educational and action game ever for the pc game. The new way to practice the speed skills in action and speed skills on solving the mathematical problem in gaming experience for the student nowadays.

\subsection{Game Mechanics}

The mechanics pitched are all from digital game developer supported develop coded into the game. None of these mechanics are explicitly declared for the player. But players can often think out what mechanic is as they play the game. The first mechanics is a timer while player playing the game. The timer is set only one minute every level for the player to complete the stage. Secondly, when dog touch the player and the player be caught by the dog. The player must run from the dog from being caught by the dog. Next, when player reach at the door, the player must click button "E" to get into the door and solve the mathematical problem. Likewise, the level will be restarted on the current level if the player falls down to on river because of the player died.

\subsection{Platforms and Minimum Specifications}

For platform in One Minute early we have decided to make an PC games from making a mobile game because the supervisor and the developer calculated due time given to make a mobile game not suitable for us to develop and design the game more advanced than making PC games. Also, PC games have variable coding and editing method linked online in the official Unity Forum, so that the game developer could learn and try our best making the game with the time the game developer have.

Table 1. Minimum Specification for the PC System

\begin{tabular}{cc}
\hline Specifications & Description \\
\hline OS & 32-bit Windows 7 \\
CPU & Intel Core i3-6300 $3.8 \mathrm{GHz} /$ AMD FX-4350 4.2 GHz Quad-Core Processor. \\
RAM & $256 \mathrm{MB}$ \\
GPU & AMD Radeon Xpress 1200 Series or NVIDIA GeForce FX 5200. \\
Hard Drive & Minimum 300MB of free space \\
\hline
\end{tabular}




\section{Storyline}

The complete storyline of this game developed into 2 stage. First, the author develop the story of this game through the outline and plot. After that, author use story board to show each sequence scene of this game.

\subsection{Outline and Plot}

Once upon a times, Jack is a student on the secondary school. Before end of the year and school, Jack must have face examination at school. Jack was the one who really hated at mathematics subject and he do not have a skill on mathematical formulas. On the mathematics examination days, every student took a place for the examination. After that, the examination started, every student answers the question clearly, but Jack having a trouble on the examination. Jack was really stress and he cannot answer the question. After 30 minutes the examination, Jack still do not write down any answers. Then, he started imagine that he at one place and one dog want to caught him. He must run from the dog and find a door to escape. After enter the door, Jack must solve the mathematical problem and the problem is based on the examination questions. He must solve the problem to save himself from the unknown place.

\subsection{Storyboard}

Storyboard help authors visually understand the scene before start to code. In this phase, the logic of this scene, narration, and question posed to the user is shown.

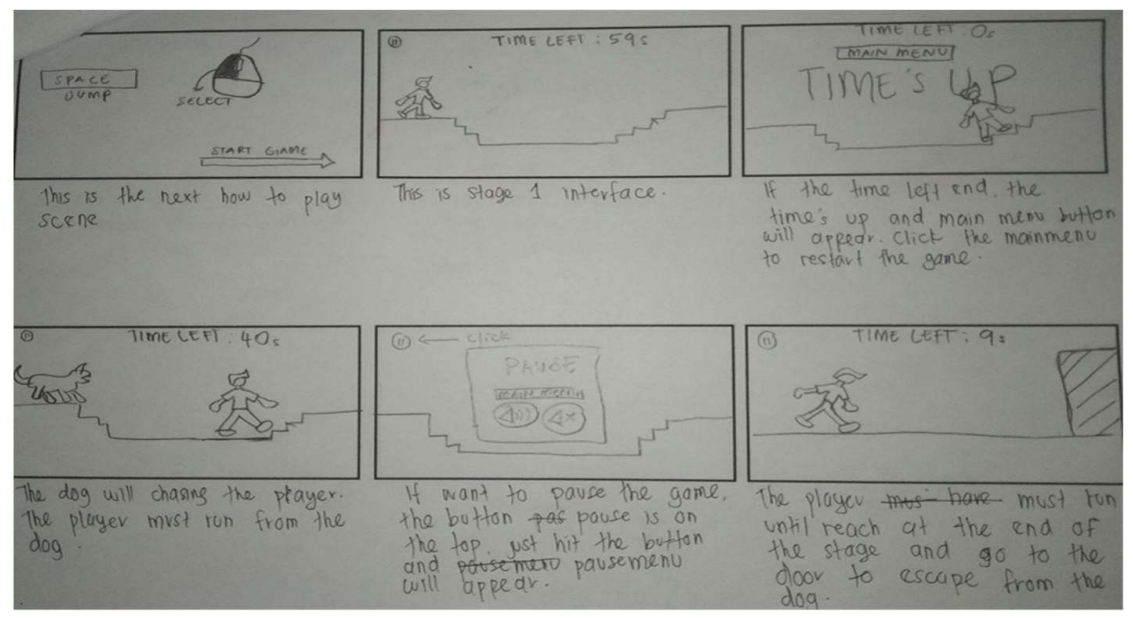

Figure 1. Storyboard: pg.1

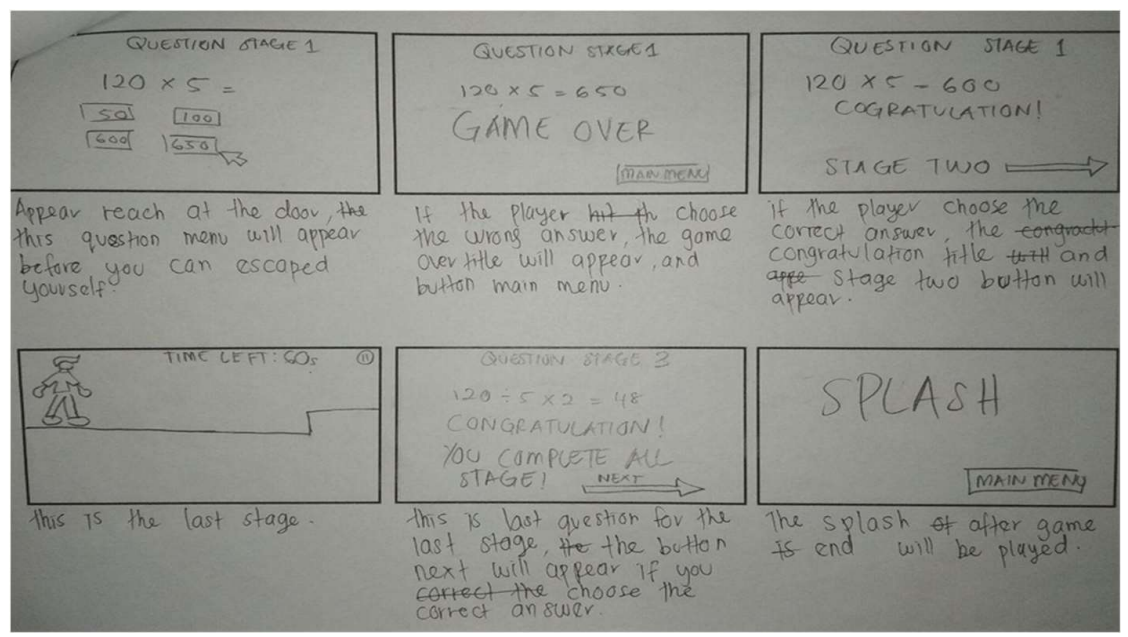

Figure 2. Storyboard: pg.2 
Amir Zuhairi Zakaria, Haslina Hassan, Hanasrullah Halim, Wan Amirah Najwa Wan Idris, Muhammad Asyraf Abdullah Zawawi, Nur Fathihah Mansor. Learning Mathematics: One Minute.

International Journal of Multimedia and Recent Innovation, vol. 2, no. 2, pp. 76-86, December 2020. DOI: 10.36079/lamintang.ijmari-0202.130

\section{Game Design}

Game design is the art of applying design and aesthetics to create a game for entertainment or for educational, exercise, or experimental purpose. Increasingly, element and principles of game design are also applied to other interactions, particularly virtual ones (see gamification).

\subsection{Concept Art and Art Style}

Game concept art for the One Minute game developer choose the vector concept art because it's easier to animated and easy to resize the character.

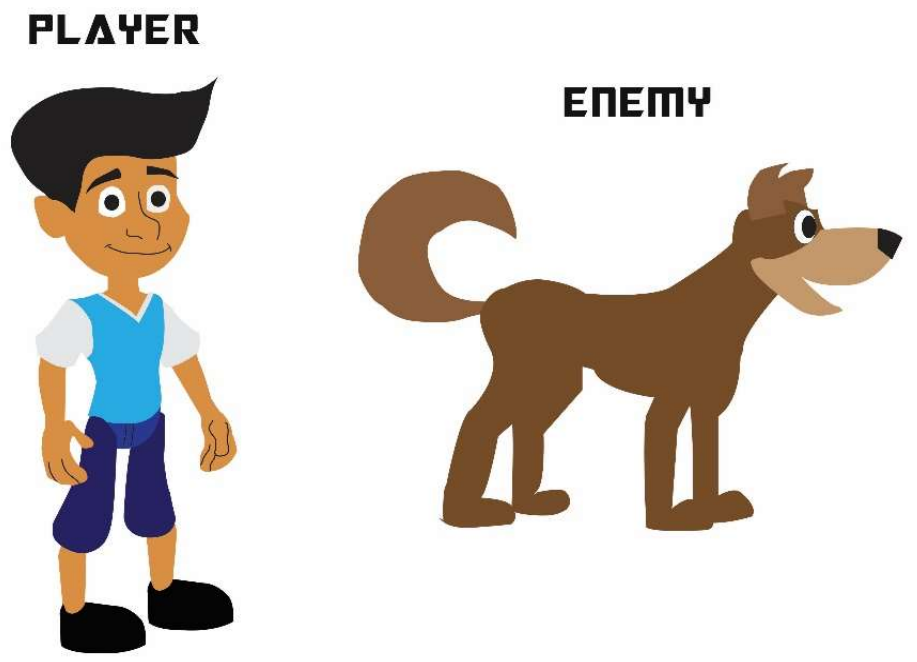

Figure 3. The Main Character: Player and Enemy

\subsection{Colours}

The most colour can be found in this One Minute game is Blue. Therefore, there are difference colour background based on the atmosphere on every level. There are have a morning, evening and night atmosphere. Meanwhile, the blue colour is the representative to the platform one minute game.

\subsection{Characters Design}

The main character in this game is JACK, the only character player will be controlled to save himself and solving the mathematical problem.

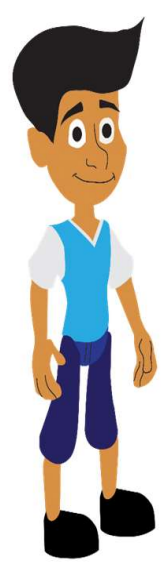

Figure 4. Character: Jack 


\subsection{Environment and Scene Design}

In the main menu of the game, user can clicked on "how to play", where user will be shown with several button to control the movement of the character. Then when user start the game, there will be a short tutorial to show how to play this game. The mission of the game that developer made is, the user must run from the dog before time's end and faced many obstacles, then the user must find the door to escape. After that, the user has to solve the mathematical problem to make the door open to go to the next level.
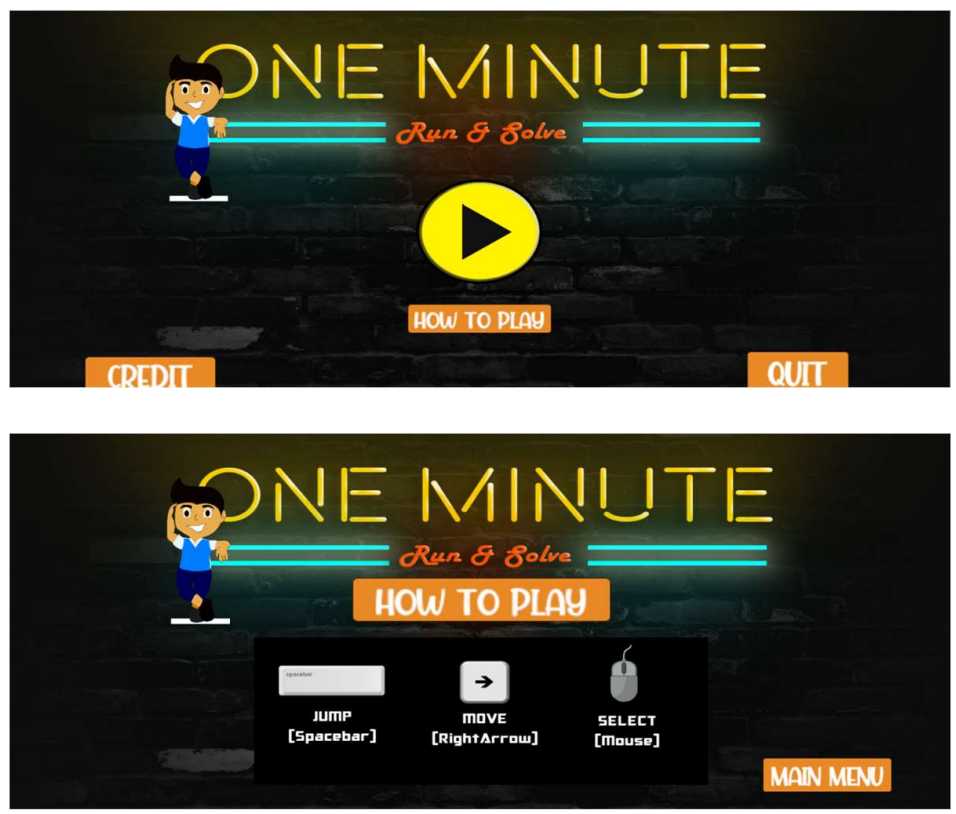

Figure 5. One Minute's Environment and Scene Design: How to Play

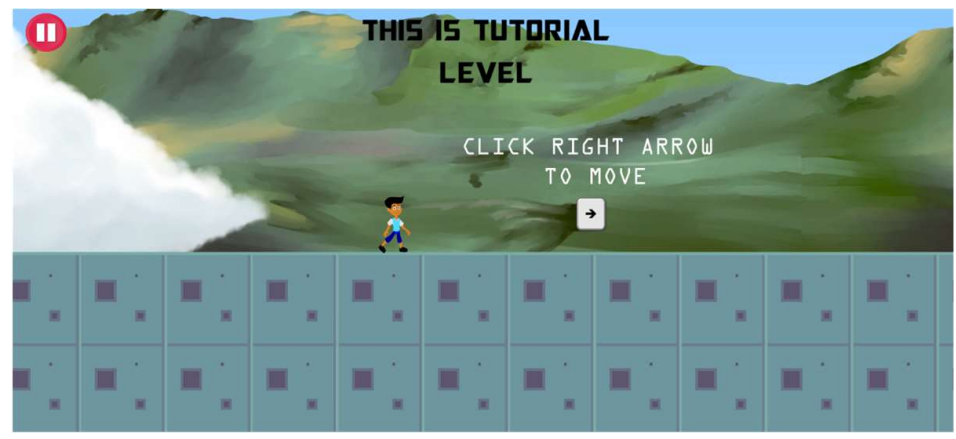

Figure 6. One Minute's Environment and Scene Design: Tutorial

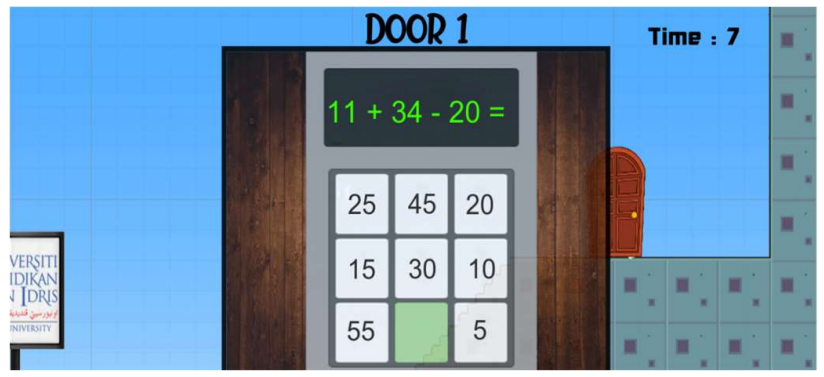

Figure 7. One Minute's Environment and Scene Design: Questions 
One minute game have a three levels to pass. Every level has a different weather. On the level one is the morning, level 2 is an evening and level 3 is a night.
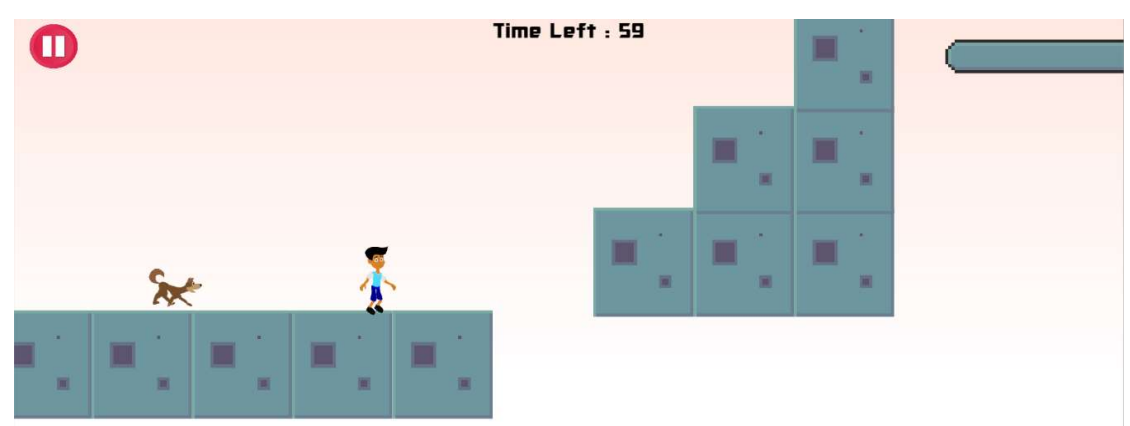

Figure 7. One Minute's Environment and Scene Design: Level 2

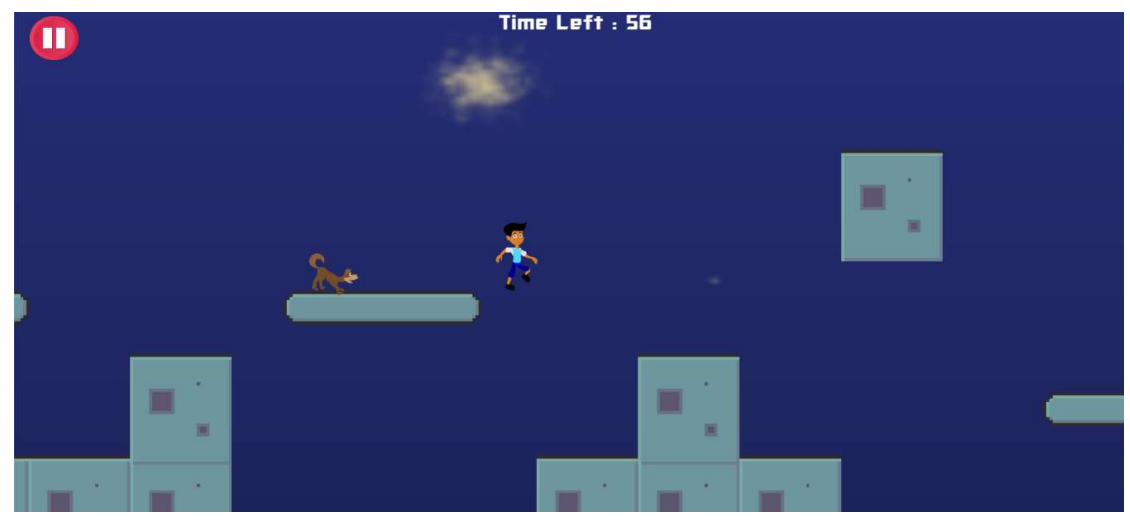

Figure 8. One Minute's Environment and Scene Design: Level 3

Head Ups Display (HUD) in this game only show the timer of the game. Game controller for this game only by using a computer keyboard and mouse. So, to move the character (Jack) the user can press "right arrow" button to move left, press "spacebar" to jump. Also, the player can press "E" button to upon the door and use the mouse to click the button on the interface.

\section{Game Development}

\subsection{Software and Hardware Requirements}

The software that the game developer using are unity game engine, adobe photoshop and adobe illustrator to design user interface, environment and character. Then, hardware requirements are one laptop with $128 \mathrm{~GB}$ solid state drive and $12 \mathrm{~GB}$ RAM to give us smooth works. Also, additional hardware that the game developer use, mouse and laptop fan.

Unity is an extremely popular game engine that affords a huge number of advantages over other game engine available in the market today. Unity offers a visual workflow with drag-and-drop

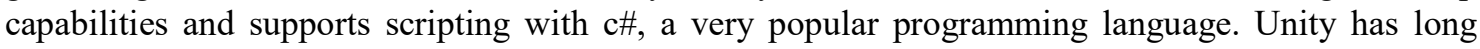
supported 3D and 2D graphics, and the toolsets for both grow more sophisticated and user-friendly with each release. 
Amir Zuhairi Zakaria, Haslina Hassan, Hanasrullah Halim, Wan Amirah Najwa Wan Idris, Muhammad Asyraf Abdullah Zawawi, Nur Fathihah Mansor. Learning Mathematics: One Minute.

International Journal of Multimedia and Recent Innovation, vol. 2, no. 2, pp. 76-86, December 2020. DOI: 10.36079/lamintang.ijmari-0202.130

\subsection{Gameplay Elements}

Gameplay is the specific way in which players interact with a game, and in particular with video games. Gameplay is the pattern defined through the game rules, the connection between player and the game, challenges and overcoming them, plot and player's connection with it. Video game gameplay is distinct from graphics and audio elements.

The objective of the game is to run from the dog and find a door to escape from the dog. The series has installments featuring both two-dimensional gameplays. In the 2D games, the player character (Jack) jumps on platform while avoid from falling to river. This game has an objective, which must solve the mathematical problem to open the door and go to the next stage. One minute introduced the educational platform game, which is the map scrolling until the next level. The developer made the One minute is fast game. The game has a timer, so the user must play the game before time's end. Then, the game has a mathematical problem to solve. One minute also a 2D platformer's game.

One minute is a game that not collecting an items or coins. The developer made the game's reward when the player reach at the door, then the user must solve the mathematical problem before time's end, if the user can solve the mathematical problem, the door will open to the next stage, that the reward to the player when the user played the game.

\subsection{Game Flow Diagram}

The game flow diagram shows in Figure 9.

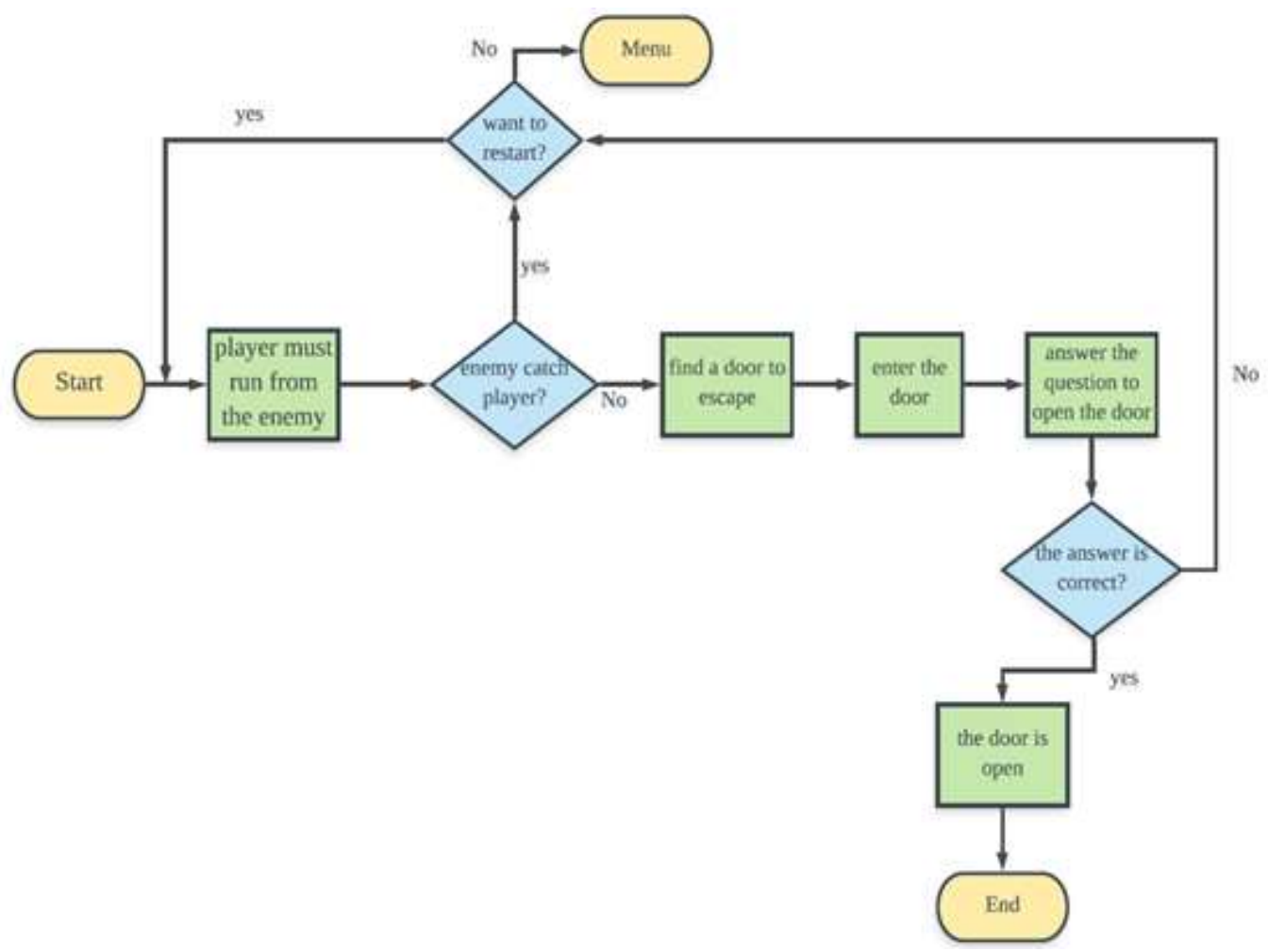

Figure 9. Game Flow Diagram: One Minute

\subsection{Screen Flow Diagram}

The screen flow diagram shows in Figure 10. 


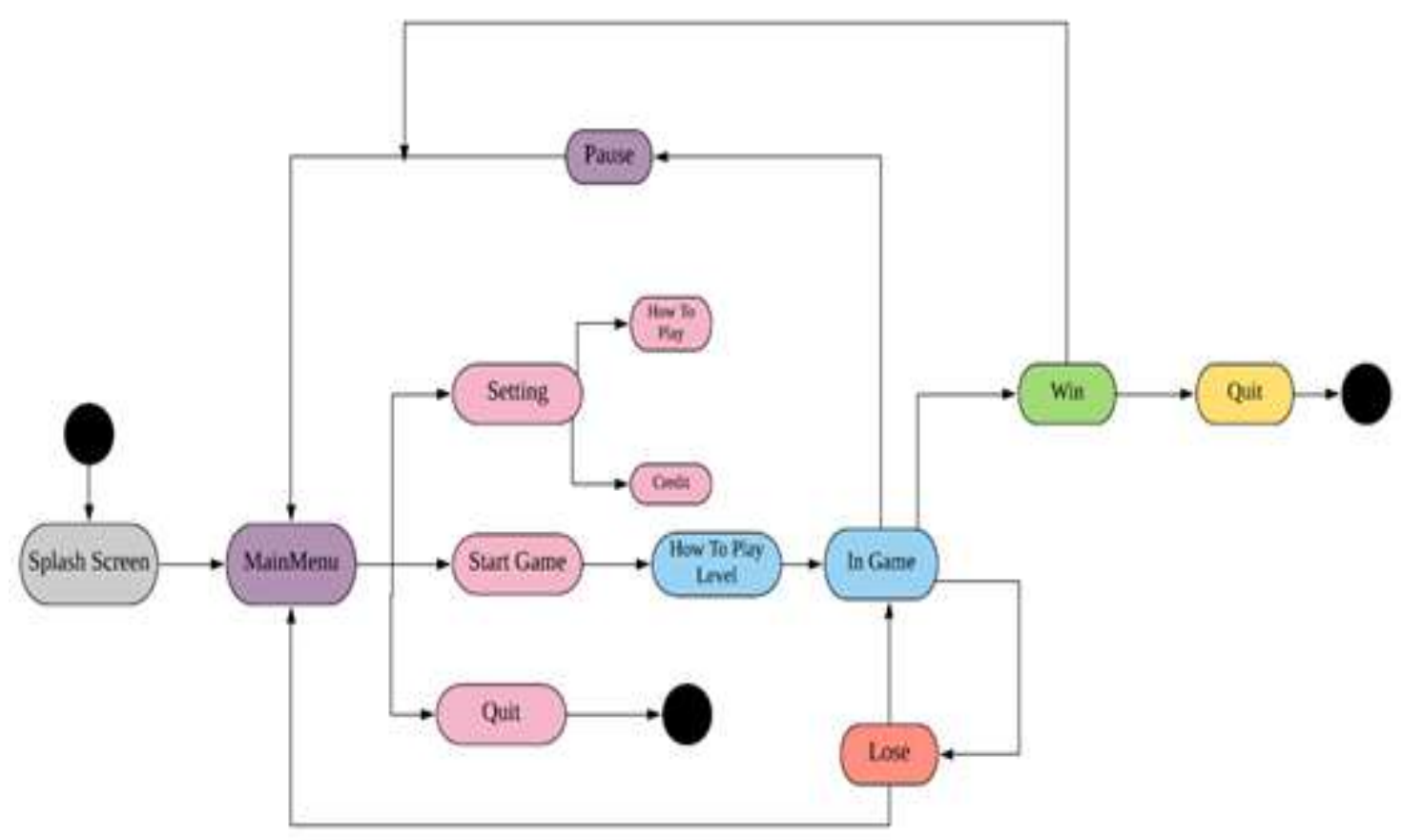

Figure 10. Screen Flow Diagram: One Minute

\section{Testing}

Game testing, a subset of game development, is a software testing process for quality control of video games. The primary function of game testing is the discovery and documentation of software defects (bugs). Interactive entertainment software testing is a highly technical field requiring computing expertise, analytic competence, critical evaluation skills, and endurance. In recent years the field of game testing has come under fire for being excessively strenuous and unrewarding, both financially and emotionally.

\subsection{Bugs, Issue and Constraints}

The game bug in this game only on the platform. While playing the game sometimes the character will be stuck at the platform and sometimes the character will step into the platform. This happen on every level of the game.

\subsection{Gamers Feedbacks}

To measure the satisfaction of the game design, each user will fill the evaluation questionnaire.

The evaluation was done on male and female with several age group, where each user will be asked to give value 1-3 (1 is for "Worst" and 3 for "Best").

The question are:

1) Was the game fun?

2) Was the game interface easy to understand?

3) Was the game play easy to play?

4) Was the graphic's good?

5) Is the game as good as the other platform games in the market?

6) Was the game being hard? 


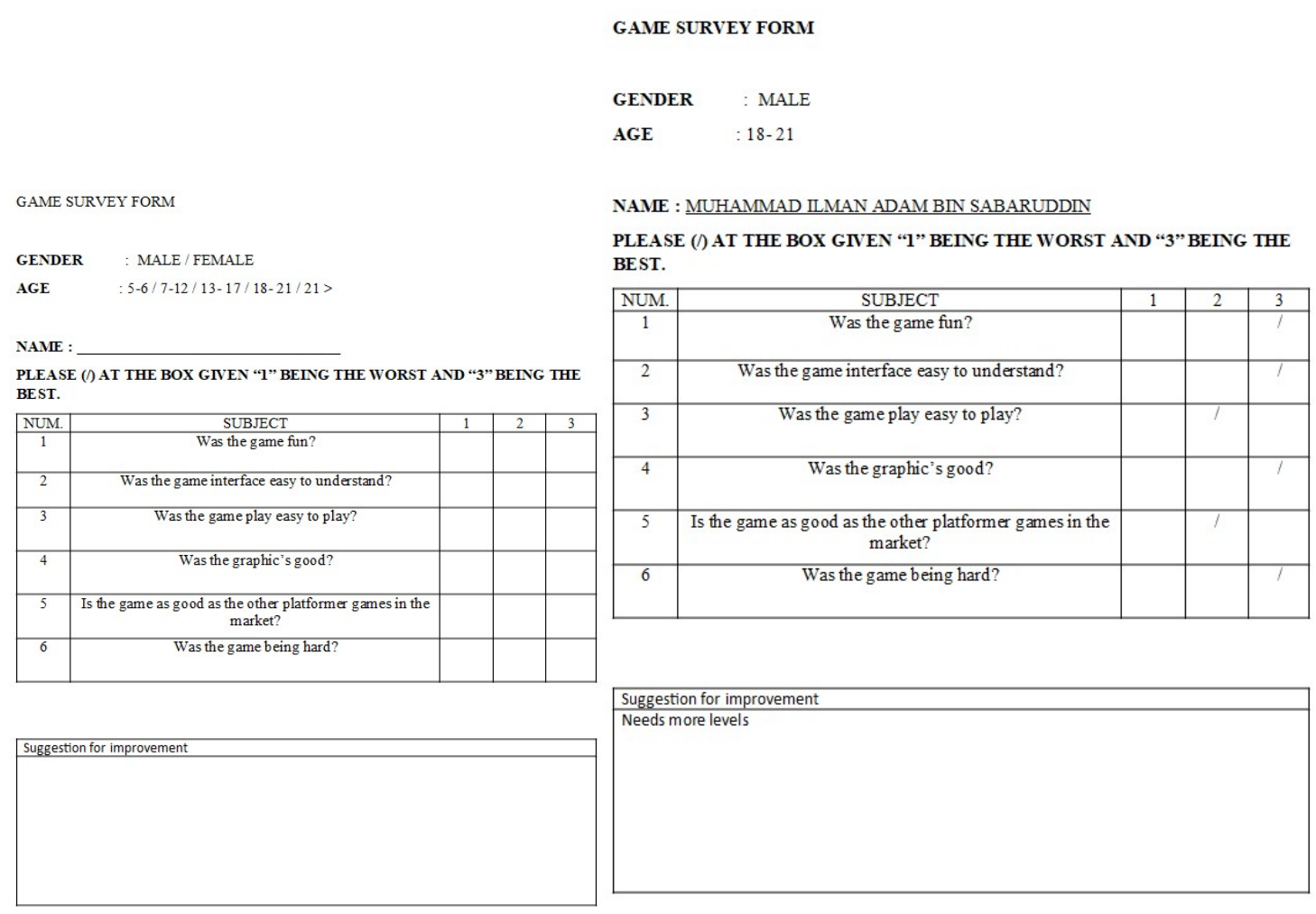

Figure 11. Game Survey Form

\section{Conclusion}

There are a few unexpected features in the making of this game. Firstly, on the solving mathematical problem should be a simple quiz, but the developer and supervisor found a way to make it more interesting and change the simple quiz to the keypad lock on the door and solve the keypad lock to open the door. Second, the character (Jack) should have parkour skill, but after week 8 making the One Minute, the developer found that it hard to do the animation and the developer found a way only use the simple movement animation.

After the game developer were done made the One Minute game and preview in the exhibition, the problem the game developer faced in the way long before the game developer made it is much more than expected. The first problem is finding out coding to make a new script, the solution found on week 7-8 in google and Unity forum also YouTube.

There's a suggestion we got in the exhibition from the some of student to make more stage and level for the game. Then, on the mathematical problem question, there a suggestion to add more times while solve the problem, because the 10 second to short while solve the problem. After that, some a suggestion to put more animation on character movement especially for Jack, the game developer already put an animation but the animation just for idle, run, and jump animation because the game developer can't make it in time because the game developer use the own character.

The suggestion for animation is when Jack fall died and make the jump animation become more smoothly. Lastly, there's a suggestion to promote the game in the faculty (FSKIK) "Fakulti Seni, Komputeran dan Industri Kreatif", because we want to support juniors and lecturer that to give a new lifestyle for the best future.

\section{References}

[1] W. A. N. Wan Idris, H. Halim, and H. Hassan, GENIUS KIDS: "Learn to Count through Games," International Journal of Multimedia and Recent Innovation, vol. 1, no. 1, pp. 1-17, 2020. doi: 10.36079/lamintang.ijmari-0101.71. 
[2] H. Halim, W. A. N. Wan Idris, H. Hassan, and I. Y. Panessai, "Learning Logic Gate through 7Gates," International Journal of Multimedia and Recent Innovation, vol. 2, no. 1, pp. 1-10, 2020. doi: 10.36079/lamintang.ijmari-0201.70 .

[3] N. H. Rahani, A. A. Bilong, M. R. Mat Suruji, and I. Y. Panessai, "Learning Logic Gates Using Augmented Reality," International Journal of Multimedia and Recent Innovation, vol. 2, no. 1, pp. 26-44, 2020. doi: 10.36079/lamintang.ijmari-0201.81

[4] M. J. Gaydos, and B. M. Devane, "Designing for identity in game-based learning," Mind, Culture, and Activity, vol. 26, no. 1, pp. 61-74, 2019. doi: 10.1080/10749039.2019.1572764.

[5] R. Dash, "The 10 Features Every Social Mobile Game Must Include," 2018 [Online]. Available: https://www.adweek.com/digital/mobile-game-features/ [Accessed: February 23, 2019]

[6] K. Thompson, "Why Gamers Should Be Part of Your Audience Strategy," 2015 [Online]. Available: https://www.thinkwithgoogle.com/consumer-insights/why-gamers-should-be-partyour-audience-strategy/ [Accessed: February 23, 2019].

[7] S. F. Sezali, A. M. Radzuan, N. I. Mohd Shabudin, and R. A. Afendi, POCKET MALAYSIA: "Learning About States in Malaysia Using Augmented Reality," International Journal of Multimedia and Recent Innovation, vol. 2, no. 1, pp. 45-59, 2020. doi: 10.36079/ lamintang. ijmari-0201.82

[8] J. Carroll, "How to Research your next Game's Target Audience for Free," 2017 [Online]. Available: from:https://www.gamasutra.com/blogs/JustinCarroll/20170313/258979/How_to Research_Your_next_Games_Target_Audience_for_Free.php [Accessed: February 23, 2019]

[9] Z. Z. Abidin, and M. A. A. Zawawi, "OOP-AR: Learn Object Oriented Programming Using Augmented Reality," International Journal of Multimedia and Recent Innovation, vol. 2, no. 1, pp. 60-75, 2020. doi: 10.36079/lamintang.ijmari-0201.83.

[10] M. A. Ishak, M. R. Kosnan, and N. F. Zakaria, "Build IoT through Virtual Reality," International Journal of Multimedia and Recent Innovation, vol. 2, no. 1, pp. 11-25, 2020. doi: 10.36079/lamintang.ijmari-0201.80 